\title{
Nanotechnology Bound: Evaluating the Case for More Regulation
}

\author{
Patrick Lin
}

\begin{abstract}
In continuing news, there is a growing debate on whether current laws and regulations, both in the US and abroad, need to be strengthened as they relate to nanotechnology. On one side, experts argue that nanomaterials, which are making their way into the marketplace today, are possibly harmful to consumers and the environment, so stronger and new laws are needed to ensure they are safe. On the other side, different experts argue that more regulation will slow down the pace of business and innovation in nanotechnology, or that self-regulation is the answer, or other opposing positions. This paper will draw out the core issues behind the debate and explain that there is more at stake than merely environmental, health and safety (EHS) worries or business interests, as it first appears. We will also suggest an alternative solution to stricter laws, since stricter laws would face formidable practical challenges, even if they are warranted.
\end{abstract}

Keywords Nanotechnology Regulation Environmental worries · Health and safety worries . Law Ethics

Whether or not current laws and regulations can accommodate nanotechnology - a science that

P. Lin $(\bowtie)$

The Nanoethics Group,

Cal Poly, San Luis Obispo, CA, USA

e-mail: patrick@nanoethics.org researchers as well as legislators are still trying to understand - is a fierce debate that came to the forefront last year with the January 2006 report by the Woodrow Wilson International Center for Scholars (WWICS) that argued for stricter policies in the US [1]. This paper will help make the debate more understandable by laying out the major positions as well as suggesting a simpler, more politically-feasible alternative to stricter laws [2].

While the aforementioned report dealt exclusively with US laws, the underlying debate is parallel to ongoing investigations around the world; the concern is the same. Because this paper does not refer to any particular law or regulation, our discussion here can be applied equally well to those investigations outside the US.

Finally, the risks we address here are environmental, health and safety (EHS) risks as opposed to, e.g., the risk that there is no democratic control over the technologies, which does not appear as urgent as EHS risks but nonetheless is an entirely separate issue deserving of its own investigation [3].

\section{The Stricter-Law Argument}

While we have not yet seen anyone or any organization clearly articulate or formalize the argument for stricter laws in nanotechnology, as opposed to implying the argument, it can be characterized as the following: 
While more and more nanotechnology products are introduced into the marketplace, some studies have already suggested that engineered nanomaterials may be harmful, for instance, causing brain damage in animals [4]. As a specific example, the carbon nanotube - a nanomaterial that consists of carbon atoms precisely arranged, like connected Lego ${ }^{\circledR}$ blocks [5], and is estimated to be anywhere from 20 to $100+$ times stronger than steel of the same weight, with chemical bonds stronger than that found in diamonds - happens to resemble the whisker-like asbestos fiber. This is troubling because the shape of asbestos fibers is what makes them so difficult to dislodge from one's lungs. Further, nanoparticles are so small, by definition, that they might easily and undetectably slip into a person's body and cells to undetermined effects [6].

There are also unknown environmental impacts of nanomaterials. Because they are created to be more durable than existing materials, it begs the question of how long they will persist in our landfills [7]. If nanoparticles can be taken up by cells, as studies have shown, then they could slip into our food chain and eventually to us - which conjures up the related scenario of food poisoning from shellfish that had fed on toxic algae and other lessons in bioaccumulation, e.g., involving the pesticide DDT [8]. Again, the effects of nanoparticles on our biology are still unknown, so food poisoning may be the least of our worries, with genetic damage and death as other possibilities [9].

So the problem is this: for many people, it seems to be commonsensical that if there are real questions about the EHS impact of nanotechnology products or any other product, then we should investigate them further before these products enter our marketplace. Society has learned that from past lessons involving such hazardous products as asbestos or lead paint or DDT into the public space.

Of course, there are laws and regulations already in place that - in theory - should prevent harmful products from ever reaching the marketplace, such as the Toxic Substance Control Act (TSCA) and Occupational Safety \& Health Act (OSHAct) in the US. But are these laws really equipped to handle nanotechnology? We will not attempt to make that determination here, particularly given the comprehensive analysis offered by the WWICS report and subsequently by other organizations [10], but we will point out that there is good-faith reason to believe that current laws are not perfect, which suggests a real possibility that they cannot account for the nanomaterials in question.

Even if one doesn't know much about the relevant laws, it is understood that laws are created based on the available facts and circumstances of the time and foreseeable future. They continue to evolve, be refined and even be repealed over time, as it should be. And given how little we know about nanotechnology - but that we know nanomaterials have novel and unpredictable properties - it would be difficult to see why we should expect current laws to not need updating (or an overhaul) as we learn more about nanotechnology. At any rate, it's better to be safe than sorry, i.e., to be open to the possibility that we need stricter laws rather than to risk damaging our health and environment, or so the "stricter-law" argument goes.

At this point, the argument would conclude that it must be a failure of current laws, such as those in the US, to prevent such products from entering the marketplace, since if there are serious and continuing questions about a product's safety, then commonsense or some version of the Precautionary Principle, which we will discuss later - would require the product is not released into the marketplace until its safety is more convincingly established.

In the case of the 2006 WWICS report, the recommendation is to strengthen existing laws and regulations as well as to enact new ones. The report also provides an analysis of the legislation relevant to nanotechnology, including: the Toxic Substances Control Act, the Occupational Safety and Health Act, the Food, Drug and Cosmetic Act, and the major environmental laws such as Clean Air Act, and Resource Conservation and Recovery Act. Again, in this paper, we will not look at that analysis to determine whether or not these acts really are equipped to deal with nanotechnology, but we will focus more on the supporting reasons behind the (implied) arguments to evaluate their soundness and consistency.

Calling for stricter laws, of course, is not the only possible response to the alleged failure of current laws. Some have already proposed a moratorium or full ban on nanotechnology research and products until EHS risks are better understood and mitigated as needed [11]. We will also not investigate this 
particular position here, since if the argument for stricter laws cannot be defended, then it seems unlikely that an argument for a moratorium, which we take to be a significantly more extreme position, can also be defended. Further, the lack of support for a moratorium, other than from the few groups that have proposed it, may indicate that this position is an over-reaction, all things considered - again, so the stricter-law argument might go.

\section{Learning from History}

If the stricter-law argument sounds a bit far-fetched or paranoid, we can look at recent US history to see where our laws have failed us in protecting the public, including industry workers, from commercial hazards. There does not need to be an elaborate conspiracy theory that such laws had been poorly designed, perhaps as a result of misinformation, corporate influence or political haggling. Rather, it is a plain fact that people are fallible, both scientists and legislators alike, especially when it comes to predicting the future - in this case about the adequacy of existing regulations to protect the public and the safety risk posed by new materials.

Asbestos, lead paint and DDT are frequently-cited case studies, as well as diet drug "fen-phen" and other pharmaceuticals. In each case, these materials made their way into the marketplace and into our homes, only to be discovered later that they are hazardous to our health and/or environment. However, one can object that these incidents, having occurred years or decades ago, are an unfair comparison to today's risk in nanotechnology. It may be offered in defense of current regulations that we have since evolved our laws and our thinking to more rigorously test new products, ever mindful to prevent such incidents from occurring again.

But why should we believe the evolution of our product and environmental safety laws have reached an end point now? Are we really that clever as to have finally created a system of safeguards to protect us from every conceivable EHS risk? Rhetorical questions aside, the following is a current example of the apparent failure of EHS regulations in 2006 alone.

Just last year, the US Environmental Protection Agency urged companies, including DuPont and 3M, to phase out their use of a chemical (Perfluoroocta- noic Acid, or PFOA) used to make Teflon ${ }^{\circledR}$, the nonstick material found in everyday items such as cookware, carpeting, clothing, food packaging and thousands of other products [12]. In use for more than 50 years, the chemical is linked to cancer and organ damage in laboratory animals. It is so ubiquitous in our environment that it is now found in the blood of nearly every American. One Teflon manufacturer has already paid more than $\$ 100$ million to settle lawsuits from residents who live near its factory, including claims of birth defects.

"The science on [Teflon] is still coming in, but the concern is there, so acting now to minimize future releases of PFOA is the right thing to do for our environment and health," explained an EPA official [13]. Environmental watchdogs support the EPA move, explaining: "It would be hard to imagine a chemical that is more widespread in our environment. It is found everywhere from babies in the womb to whales in the ocean. And beyond that, it is indestructible in the environment. It lasts forever" [14].

So given this current and apparent failure of US regulations to discover or account for EHS risks posed by Teflon - never mind other continuing controversies, such as currently-available pharmaceutical drugs that might unknowingly cause severe health problems - a similar failure with respect to nanotechnology is not just possible but highly plausible.

Of course, it is perhaps unreasonable to expect that we can guarantee that commercial products, particularly emerging technologies, are completely safe. But it seems backwards to release a product into the marketplace and then conduct EHS testing needed to answer basic questions surrounding the product. For instance, there are continuing questions on whether mobile phones may cause a generation of people to have brain cancer, infertility or other health problems [15]. Also last year, a group in Finland announced that it is studying the effects of mobile phone radiation on human skin, given that previous tests have shown cellular shrinkage which may degrade our bodies' ability to filter out toxins and other dangerous proteins [16].

As with Teflon, this is the exactly the kind of scenario that we want to avoid by now discussing regulation in nanotechnology. It would be a catastrophe on many levels if mobile phones are shown to be hazardous to our health, since we have already been using such devices for more than a decade. If they are 
hazardous, we would hope that risk would have been caught by EHS processes designed to protect against this contingency. But since real, basic questions are still open surrounding mobile phones, as just one product, many suspect that EHS regulations today need to be repaired, independently of any special risks posed by nanomaterials.

Returning to nanotechnology, the "commonsense" we referred to in constructing the argument above has been formally called the Precautionary Principle (PP), and it is worth discussing here briefly, since it plays a critical role in the argument. The PP, or at least one version of it, essentially states: if an action might possibly lead to an unacceptable consequence, then we should refrain from that action until that risk is mitigated [17].

As it applies here, the PP seems to dictate that if introducing nanotechnology products into the marketplace now might possibly lead to the unacceptable consequence of serious harm to people or the environment, then we should refrain from that action until that risk is mitigated - in this case, by implementing stronger laws and regulations. Note that for the PP to work, the risk needs to be credible and not just a bare or logical possibility. Given previous and ongoing research, it is a credible claim to say that, at best, we are uncertain whether nanomaterials are safe, and at worst, there is good evidence to show they are not.

In the case of the Teflon chemical, even though studies have not definitively proven that it is harmful to humans in the amounts present in our everyday lives (otherwise a much stronger and immediate ban perhaps would have been proposed), there is enough data to suggest a real risk to the environment and our health. So the EPA seems to be guided by the PP or something similar in concluding that companies should produce less of this chemical, in case that its presence in consumer goods and in manufacturing emissions is truly harmful. In other words, the EPA decided that the best course of action is to err on the side of precaution, even though a $\$ 2$ billion-a-year business is reputedly at stake [18].

\section{Objections to the Stricter-Law Argument}

If we take the preceding as an accurate characterization of the stricter-law argument, then we might (loosely) formalize the argument as the following set of premises $(\mathrm{P})$ and conclusions $(\mathrm{C})$ :

(P1) Some prima facie evidence exists that some engineered nanomaterials may be harmful to EHS interests.

(P2) Current laws may be inadequate in accounting for EHS risks in nanotechnology (as a general liability of any law that is now relevant to an area that did not previously exist or was not properly/fully considered during the legislative or regulatory process).

(C1) Therefore, there is a possibility that nanotechnology, as it advances and absent stricter laws, may lead to EHS harms.

(P3) EHS harms are an unacceptable consequence, especially since our laws and some governmental agencies exist specifically to protect us from those harms.

(P4) Commonsense suggests we should adopt the Precautionary Principle in this case, which states that: if an action might possibly lead to an unacceptable consequence, then we should refrain from that action until that risk is mitigated.

(C2) Therefore, we should refrain from allowing nanotechnology to proceed without taking some action to mitigate nanotech's EHS risk.

(P5) We can mitigate nanotech's EHS risk by either enacting a moratorium or implementing stricter laws.

(P6) A moratorium on nanotechnology research or commercialization has limited support and may be an over-reaction, so it is not a viable or reasonable option.

(C3) Therefore, the action we should take, if we want nanotechnology to proceed, is to implement stricter laws.

There has been much debate over the conclusion of the stricter-law argument. The objections, both actual and possible, to that argument include the following, in order of the weakest to strongest, as we see them:

(a) Ordinary Material Objection: Nanomaterials are not any more harmful than other materials, so they need no special regulations;

(b) Status Quo Objection: Current regulations are enough to safeguard the public from these harms; 
(c) Precautionary Principle Objection: The Precautionary Principle should not apply here, so the entire argument that rests on it is flawed;

(d) Self-regulation Objection: Self-regulation, not more governmental regulation, is the answer;

(e) Other Harms Objection: Stricter regulation would stunt the growth of a nascent nanotechnology industry;

(f) Future Harms Objection: More than the usual, near-term economic harms cited in (e), there may be more serious harms in the future if the nanotechnology industry were hindered now; and

(g) Better-Us-Than-Them Objection: Increasing regulation only puts that nation at a disadvantage with others that may then develop and reap the benefits of nanotech first;

Though some of these objections can be and have been combined, we will consider each separately in the following. The last few objections are the most compelling, so we will spend more time on those positions than others in our discussion.

\section{(a) Ordinary Materials Objection}

This objection asserts that existing laws and regulations are adequate to account for nanotechnology, because nanomaterials are essentially the same kinds of substances that we have been using for decades. That is to say, a carbon nanotube is still only made up of carbon, and nano-sunblock is still only made up of zinc or titanium oxide - and these are materials that current regulations have proven sufficient to handle. In some cases, nanomaterials are simply much smaller versions of the familiar thing. In other cases, they are the same material with a different molecular arrangement. Therefore, we do not need stricter laws to account for nanotechnology.

In fact, nanotechnology is something that has arguably existed since the beginning of the world, if not earlier: "Nanostructures - objects with nanometer scale features - are not new nor were they first created by man. There are many examples of nanostructures in nature in the way that plants and animals have evolved. Similarly there are many natural nanoscale materials...catalysts, porous materials, certain minerals, soot particles, etc. that have unique properties particularly because of the nanoscale features" [19].

\section{Analysis}

In the formalized argument stated above, this objection disputes either premise $\mathrm{P} 1$ or $\mathrm{P} 2$, or both, and therefore conclusion $\mathrm{C} 1$ as well as the dependent conclusions $\mathrm{C} 2$ and $\mathrm{C} 3$. However, the objection seems scientifically naive at best and contradictory at worst. First, it is precisely the different molecular arrangement of the same materials that creates different properties. In a certain arrangement, carbon can be made into pencil lead and useful for writing; in another arrangement, it is a diamond; in yet another, it is a carbon nanotube that, for example, is useful in building lighter cars or aircraft. Therefore, it is not so much the issue that nanotechnology works with common materials, but rather that by manipulating these materials at the nanoscale, we can create uncommon results - results that today's laws and regulations could not have anticipated.

Second, it is not just the molecular arrangement that gives nanomaterials their unique properties; it can also be their size. For instance, aluminum is often considered an everyday, safe element, e.g., soda cans are made from it. But if aluminum is ground up fine enough into dust, it can spontaneously combust in a highly energetic reaction with air. Further, nanoparticles are, by definition, so small that existing air and water filters would be unable to prevent their escape from manufacturing facilities - opening the possibility for toxic emissions that affect workers and the outside environment [20].

Given their size, nanomaterials may also be able to slip by current methods of testing for safety and health risks. In other words, current regulations that require such testing may not be enough, if the testing methods they require cannot catch nanosized materials. Recognizing this challenge, researchers at UCLA, for instance, last year announced devising a new approach to nanotoxicology [21].

Finally, the Ordinary Materials Objection also seems to be a case of "wanting to have your cake and eat it too." The allure of nanotechnology in the first place is that the materials we are creating have novel and useful properties that we are still trying to understand and exploit. So it would be inconsistent to say that these nanomaterials are nothing special that we need to worry about, when the entire point is that they are extraordinarily special. As something special and unpredictable, it would be reasonable to think that 
they might be more (or less) hazardous or toxic that ordinary materials of the same element or chemical which is exactly the concern that is prompting calls for more regulation.

\section{(b) Status Quo Objection}

This objection to the stricter-law argument asserts that, as a matter of fact, current regulations are enough to safeguard the public from these harms. They have served us well over the years, and without definitive proof that nanomaterials are actually harmful in consumer products or manufacturing, it is premature to subject the nanotechnology industry to more regulations.

\section{Analysis}

This objection disputes premise $\mathrm{P} 2$ in our formalized argument, thereby throwing into question all conclusions from $\mathrm{C} 1$ to $\mathrm{C} 3$. Our evaluation of this objection has already been discussed in the preceding section, where we pointed out that today's controversy over Teflon, as just one example, shows that current laws and regulations are fallible and probably do not fully protect us from EHS risks in all consumer products or their manufacturing.

Further, even if current laws are adequate to account for nanomaterials in production today and in the near future, the industry is still learning about the science and working on new materials, and these materials may slip past existing laws. Either way, it is also prudent to believe that the processes we have established to regulate business in general are imperfect and will continue to be a work in progress, as long as businesses and research organizations continue to innovate. Therefore, we should be open to the possibility that current laws and regulations are not enough, particularly when the consequences of their failure may be catastrophic. This objection, therefore, does not appear to be defensible against the stricter-law argument.

\section{(c) Precautionary Principle Objection}

This objection maintains that the Precautionary Principle (PP) is not an obviously-correct or com- monsense rule that we should follow, and therefore the stricter-law argument falls apart, since it depends critically on the PP. The most serious criticism we examine here is that the PP represents a risk-averse strategy that is too conservative, at least as it applies to the considered case of nanotechnology where the EHS risk is still unclear [22].

Risk aversion, the argument goes, is not the only workable strategy in life, business or politics. After all, if Americans never took unnecessary or perhaps unreasonable risks, then we never would have accomplished such things as expanding the country westward to California, inventing the airplane and putting a man on the moon. In fact, America was built on the backs of explorers and frontiersman, such as Christopher Columbus and Captain John Smith, who risked and sometimes lost everything. And many other nations can say similar things about their forebearers, pioneers and inventors.

Such may be the case with nanotechnology: it is a new frontier in science that, while admittedly contains unknown danger, also holds much promise. However, if we were to follow the PP, we may lose a great opportunity to develop a science that has been called "the Next Industrial Revolution" [23].

\section{Analysis}

This objection attacks premise P4 in the formalized argument, evoking powerful emotions of national pride and adventure, so it may appeal to many. However, it is unfair to compare our current debate on strengthening laws relevant to nanotechnology with, say, the Wright Brothers' debate on whether they should jump off a cliff on what amounts to a bicycle-powered deathtrap, or with any of the other situations cited above.

One reason is that the individuals associated with above events, from Christopher Columbus' crew to Neil Armstrong, presumably had consented to such risks. Their decisions more or less directly affected only their own lives. But in our considered debate surrounding nanotechnology, countless people may be put at risk without their consent. Indeed, surveys have shown that most Americans are unaware of what nanotechnology is or have not even heard the word before, so it would be impossible for them to give informed consent anyway, even if asked [24]. 
The issue of rights might be relevant here. Our basic human right to not be unjustifiably harmed plausibly entails a right to not have one's life unjustifiably endangered or otherwise put at risk of significant harm. That is, not only are we morally barred from harming others without just cause, but we should also not put others at risk of such harm or even cause theoretical or statistical harm. Without their consent to be subjected to such risk, ignoring the PP in the case of nanotechnology may violate this right.

Of course, one possible reply to this is that by participating in a democratic system such as that in the US, we are in effect "consenting" to the outcomes of elections, ballot propositions as well as any legal actions of the leaders we elect. So if an elected legislative body were to pass some measure or law that runs contrary to the PP, then it can be said that we had consented to such a decision by electing politicians prone to such aggressive policies. If current laws and regulations are allowed to stand as they are, that is a decision by which the public must abide (or seek to reverse through the established political channels).

However, political theorists have pointed out that we cannot consent to unjustifiably lay down our lives or submit to unreasonable harms, since that would defeat the very purpose of government in the first place [25]. So extending this line of reasoning to our discussion here, it may be argued that we also cannot consent or countenance policies that lead to harm to our persons.

At any rate, it does not seem unreasonable to suggest that if the stakes are high enough - as apparently is the case with nanotechnology, where real human and animal lives as well as the environment are at risk - then minimizing risk should be a guiding principle, rather than, say, the pursuit of profits, adventure or glory. Individual actors may arrive at a different conclusion, depending on their tolerance for risk and what value they place on their own welfare. But if the decision involves risking the welfare of countless others, it may be irresponsible to not adopt something like the Precautionary Principle - in which case the stricter-law argument again survives [26].

\section{(d) Self-regulation Objection}

This position opposes more governmental regulation as a way to mitigate EHS risks. Rather, it advocates self-regulation as an alternative, such that if any additional regulation is needed, it should be left up to the industry to decide what measures are appropriate.

There are several reasons why this view is attractive to many [27]. First, it promotes a smaller governmental footprint in business and individual lives, so it instantly appeals to libertarians and some conservatives. Also, it may make more sense for the nanotechnology industry, that presumably knows its field the better than lawmakers do and have a real stake in its work-processes, to devise and implement any regulations, rather than some distant bureaucracy whose edicts are inevitably borne from political compromise. By monitoring one's own work, selfregulation fosters a sense of responsibility within the industry. Further, self-regulation seems to work, as evidenced by any number of professional code of ethics.

\section{Analysis}

A persistent criticism to the idea of self-regulation is that it seems to let the proverbial fox guard the hen-house, or in other words, there is a sizable conflict of interest [28]. Can we trust an industry - any industry - to make its own rules when money is involved? Can they fairly create processes that protect EHS interests of the public, even at the expense of their own interests, financial or otherwise?

Some have called it a pragmatic paradox to ask a person or organization to obey the law and, at the same time, be the law [29]. Because there is no real separation between those enforcing regulations and those subject to the regulations, the door seems to be open for self-imposed regulations to be selectively enforced and for potentially covering up illegal or unsafe practices.

Of course, an enlightened company might see that it is in their best interest to deliver only safe products, since harming one's own customers is counterproductive to one's reputation and business as well as opens the company to possible litigation. But will every company arrive at the same conclusion, ignore shortterm gains for long-term interests and follow the rules? For self-regulation to work, nearly every industry actor needs to comply, since all it takes is one clever company to sidestep industry-imposed regulations for possible catastrophe to occur, i.e., the 
EHS risks may still exist and are not sufficiently mitigated by self-regulation.

The diagnosis of why actors fail to cooperate even though it is in their better interests to do so - also known as a "Prisoners' Dilemma" - is well covered in literature [30]. As groups such as OPEC have shown whose members are notorious for ignoring their own self-imposed quotas for oil production, even though compliance gives them a means to control greater oil prices - it is a real challenge to get organizations to do what they have committed to, even if breaking that commitment will make them worse off in the long run.

Further, if governmental regulations are believed to be imperfect because they contain political compromise, it is unclear why matters should be different with self-regulation. An industry coalition is merely comprised of companies, research organizations and individuals of varying influence and interests collectively representing a government of sorts, albeit a smaller and more direct model, with the same tendencies and weaknesses.

In nanotechnology, the problem is worse, since there is no single "industry" that encompasses all the possible or even current applications in nanotechnology. Unlike associations for architects, engineers, lawyers or medical doctor, there is no such group for nanotechnologists, because their work and interests are so varied - cutting across myriad industries and companies, from Applied Materials to BMW to L'Oreal to Merck to Zyvex and countless others. In fact, discussions about nanotechnology are usually prefaced with the disclaimer that "nanotechnology" itself is a misnomer and properly should be "nanotechnologies" to reflect the different lines of research and applications.

Given the above concerns, it is not apparent that self-regulation is a more viable or desirable alternative to governmental regulation. Further, we should note that this objection does not dispute the soundness of the stricter-law argument: it agrees that something should be done to mitigate risk associated with nanotechnology. That is to say, it does not dispute any of the premises or logic in the formalized argument. It does not even dispute any of the conclusions, including $\mathrm{C} 3$ that mandates stricter laws; rather, the objection merely prefers self-regulation to governmental regulation.

Even if the reasons given for self-regulation over governmental regulations are defensible, they appear irrelevant to attacking the stricter-law argument; therefore, the stricter-law argument survives this objection. At most, the objection might highlight the stricter-law argument, as formulated in this paper, as incomplete: further argument is needed to show that the stricter laws need to be mandated by government agencies as opposed to by an industry coalition, which would then be the point of attack for this objection.

\section{(e) Other Harms Objection}

This objection, perhaps the most popular of the seven considered, suggests that if stricter laws were imposed, there would be unacceptable costs or harms to the nanotechnology industry now. Few objectors have specified these costs, but we can imagine what some might be. If tougher regulation makes it more difficult for a nanotechnology product to be delivered to market, e.g. due to extended product testing cycles or more comprehensive environmental impact reports, then a business can reasonably expect to generate less revenue over a given period, since they no longer or won't as quickly have that product on the shelves.

This also means businesses might not be able to afford to keep the same number of researchers or other employees on staff, leading to a loss of jobs. Without as many active researchers - including those in academic or other non-business labs, to the extent that these new laws affect their work - nanotechnology will not advance as quickly as it might otherwise have. And if other nations do not have the same stringent restrictions that we do, the US may suffer a real competitive disadvantage globally. (We will discuss other potential costs later, but these seem to be the primary ones associated with this objection.)

Indeed, a recent report from Cientifica argues that today, even without the stronger regulations proposed, the pace of funding, research and development in the US is not fast enough to sustain business efforts and compete with other nations [31]. The report warns that not enough government spending in nanotechnology is focused on areas of immediate commercial impact. And accessing this funding is a slow process, taking an average of 2 to 3 years before it even reaches the lab. The report also finds that, as a proportion of its gross domestic product, the Japanese government spends three times as much on the 
technology than the US does. As it applies to the Other Harms Objection, this report would lend defense to the claim that the nanotechnology industry needs more support, not more hurdles that would slow it down further.

\section{Analysis}

This objection disputes premise $\mathrm{P} 3$ in our formalized argument above. By itself, it does not deny that there may be EHS harms from nanotechnology (i.e., it does not dispute conclusion $\mathrm{C} 1$ ), but it asserts that EHS harms are not an unacceptable consequence if stricter laws would cause greater harm, thereby questioning conclusions $\mathrm{C} 2$ and $\mathrm{C} 3$.

The objection - that an action will have burdens on the business side - is a common response to nearly any proposal to introduce new tax or regulations. For instance, a higher minimum wage would mean that some businesses will need to spend more on payroll and perhaps pass along that expense to customers in higher prices. And considering that some of these companies might be barely profitable, it seems reasonable to predict that some may go out of business. They simply cannot afford to spend more, without somehow increasing revenue - and if they knew how to do that, they probably would have done it already. (Though even in hindsight, it is not clear how many, if any, legitimate businesses have closed as a direct result of paying a higher minimum wage.)

But a loss of jobs and revenue by itself is not necessarily a bad thing, if there are other redeeming results. For instance, even if nanotechnology products were allowed to reach the marketplace unhindered by new or strengthened laws, their success would inescapably cause other sectors and companies to lose jobs, just as word processing software displaced workers in the typewriter industry. A nano-paint company whose products are more durable and scratch resistant than traditional paint may likewise displace competitors, so a loss of jobs and revenue by somebody may be unavoidable. This is an illustration of "economic Darwinism", presumably a desirable situation where new, better innovations and businesses replace older, less efficient or less effective ones. In the nanotechnology regulation debate, the economic harms potentially caused by stricter nano- technology laws may be offset by the lives, animal and human, that the stricter laws potentially save.

So while we can empathize with the Other Harms Objection, it appears to be one-sided and ignores the fact that there must be a tradeoff. Every proposal has its costs, and there seems to a necessary downside for somebody. But there is also an upside or benefits too; otherwise, the proposal would have not been worth making in the first place, even if there were no costs. The challenge is not just to identify these costs, but also to evaluate the costs and benefits to determine whether the proposal is worthwhile overall.

For instance, we know that for every bridge or skyscraper that is built, a certain number of construction workers can be expected to die or be seriously injured on that job. This is not a trivial concern - but should it be enough to derail a bridge or skyscraper project? We loathe to put a price tag on a person's life, such as in making a cold, utilitarian calculation of lives lost versus economic benefits from the bridge. But the fact is that such calculations must happen in real-world projects.

As it applies to the issue at hand, the benefit of stricter regulations is that we reduce the risk that nanotechnology may pose to the public, industry workers and the environment. Does reducing that risk justify the potential loss of profit, jobs and competitive advantage in the nanotechnology industry?

Finding the answer to this question depends on additional considerations: How much would these new regulations reduce the risk - a substantial or an incremental amount? How much burden exactly would these regulations put on the industry? If we could quantify likely and worst-case scenarios, how many consumers might be harmed - and what kind of harm - without new regulations, and how much would the industry lose in jobs and profits? These are questions that will require more research to answer, although a common intuition might be that people should be valued more than profits, no matter how much is at stake for an industry - a point we will not take up in this paper.

However, matters can quickly become more complicated without debating that point, when one considers the role of rights in this discussion. If we have a basic human right not to be unjustifiable harmed and the government has an obligation to protect its citizens (from internal and external threats, including unsafe commercial products), then it seems 
that stricter regulations are needed to protect this right and fulfill the government's obligation.

But on the business side, it is less clear what rights would be violated by the introduction of stronger laws. Do we have a right to the jobs that might be lost in nanotechnology? Do businesses have a right to develop products that are in compliance with existing laws (or is there a corporate moral responsibility to employees and customers, beyond what is required by law)?

Even if we answer "yes" to these questions and others, it may be useful to note the types of rights at stake. Our individual right to not be unjustifiably harmed is a "negative" right, meaning that it requires others from not interfering from an action [32]. But any business-related rights seem to be "positive" rights in that they require some good or service to be provided [33]. As other examples, our right to free speech is a negative right, since it requires that others refrain from preventing us to speak our minds. In contrast, our right to education is a positive right, since it requires that we are provided with access to learning.

The relevance of this distinction is that negative rights, it has been argued, are stronger than positive rights [34]. Negative rights can be observed by, for instance, simply not interfering with someone else's speech or not harming a person unjustifiably; no action is needed. But positive rights are more difficult to respect, since they require an action or series of actions that may take some effort, for instance, hiring teachers and building classrooms in order to provide a public system of education. Because negative rights take less effort to respect, it is less forgivable to violate a negative right [35].

So even if the jury is still out on whether the cost to business and industry is really worth the reduction in EHS risk from stricter laws, there seems to be prima facie reason to favor stricter laws on grounds that it protects our negative right to not be harmed, which must take precedent over any positive rights of the nanotechnology industry - and it is not even clear what rights are at stake in business and industry. Another prima facie reason for some individuals may be based on the aforementioned "people over profits" intuition.

We should note that the Other Harms Objection, by itself, does not dispute the soundness or logic of the stricter-law argument. Rather, it attempts to show that P3 should not be accepted by shifting the focus to a contest between benefits and harms, suggesting that more damage than good will be caused by stricter laws - which we are taking here to be, at best, an open question or stalemate. Therefore, in our analysis, the stricter-law argument appears to survive this objection for the time being.

Further, we should also note here that the Selfregulation Objection and the Other Harms Objection are incompatible, i.e., it is logically inconsistent to hold that stricter regulation would hinder a fledgling nanotechnology industry and that self-regulation is the answer. Any self-imposed regulations nevertheless represent more regulations than which currently exists. But if it also believed that more regulation would stunt industry growth, then self-regulation too must impede industry progress - unless self-regulating is a hollow or token gesture to appease regulators and the concerned public.

\section{(f) Future Harms Objection}

If there is something reasonable, but not completely convincing, about the Other Harms Objection, then we can perhaps strengthen it here by pushing its timehorizon farther out, giving the argument more consideration [36]. In doing so, we can suggest that the preceding objection really did not consider enough harms: it looked only at immediate or shortterm harms associated with stricter laws. But nanotechnology is something that is forecasted to give humanity profound benefits once it matures, and we have yet to consider those goals in pursuing nanotechnology. If we slow the industry down today, will that prevent or hinder us from realizing these benefits later - benefits that may plausibly outweigh EHS risks that exist either today or in the future?

In the following, we will briefly present some of the risks of moving too slowly in nanotechnology that could be advanced by the Future Harms Objection, which is not an objection we commonly see but is a view held or implied by at least some nanotechnology advocates. Taken together, these risks raise the stakes involved in the stricter-law debate and may present a more compelling challenge.

\section{Economic Benefits}

Nanotechnology is predicted to be a trillion-dollar industry by 2015 [37]. While other countries - 
including Brazil, China, South Korea, India, Israel, Russia and many European nations - proceed at full speed ahead, the US and any other nation may lose significant economic benefits if it is not among the leaders in nanotechnology. Depending on the scale of economic benefits a nanotechnology industry or industries can provide, many lives in the US may be saved or made better, given that poverty is one of the greatest determinant of life expectancy. Further, the jobs that stricter US laws might deprive might not simply be as a result of preventing new lines of business from being created, but those are jobs that now might be lost overseas, if another country or countries take the lead and develop those commercial innovations.

So the problem is that, while the US may pride itself for being democratic in recognizing and considering various interests among its population, from business owners to environmentalists, other governments may not be constrained by this guiding principle and can push nanotechnology research and products ahead, unencumbered by laws and regulations that may be stricter in the US. This may lead to a loss of economic benefits on a larger scale than previously considered, since in this scenario, jumpstarting the nanotechnology products industry then would take more than firing the research and manufacturing facilities back up; we would then need to play catch-up in competing with other nations who may have a significant, potentially insurmountable, head start.

\section{Military Implications}

Nanotechnology promises to have significant military applications, and indeed the military is a key driver of nanotechnology research for many nations, including the US. These predicted innovations include new offensive capabilities (such as energy, robotic and stealth weapons) and defensive (such as stronger armor and better detection and jamming capabilities). The military is also leading the charge to develop medical advances that can be used on the battlefield and better information systems used for intelligence gathering as well as control and command centers. With nanotechnology, production speed of military assets can be increased to give a sizable advantage in numbers alone, let alone their efficiency.
Nanotechnology, then, has the potential to take a military force into the next generation and beyond. And to the extent that a balance of military powers around the world is needed to maintain some semblance of global security or peace, nanotechnology could disrupt this balance, if it is developed unevenly by current military powers. Never mind how a nation would feel to lose its position or influence in global affairs, a more worrisome question to many is: what would be the effect of a nondemocratic government having the most advanced nanotechnology capabilities or developing them first? Would that subject the nation to a foreign attack that cannot be answered in kind? The potential loss of security and lives needs to be added to the list of harms, if stricter laws are also applied to or affect military developments.

\section{Reversing Environmental and Health Risks}

The current debate over stricter laws is grounded in concerns that nanotechnology products today may be harmful to the environment and our health. But it is also important to note that nanotechnology is also expected to enable us to reverse many conditions that afflict our environment and health. Nanotechnology is being applied, for instance, to create better filters that can provide clean water and air, which can help Third World countries that need it the most.

Likewise, it can help ameliorate the large environmental impact of dirty industrial processes, including those having to do with energy generation. New and additional sources of energy, such as cost-effective solar energy, will reduce or eliminate pressure on current natural resources. Chevron recently announced working on nanotechnology that can convert tar found in sand into useable oil, which would serve a dual purpose of cleaning up the environment [38]. In the distant future, nanotechnology may be able to rebuild our depleting ozone layer or create nanobots that can "eat" oil spills and other contaminants.

Beyond environmental benefits, nanotechnology is being applied to agriculture to better feed the hungry and to medicine to save more lives. So if we are worried today about EHS risks in nanotechnology products, we should also keep in mind the EHS risks they could mitigate or solve with a sufficient time horizon, including today's risks. 


\section{Analysis}

This objection is more robust that the preceding one for a number of reasons. First, it adds longer-term benefits (or harms from not pursuing nanotech) to the list of those that should be considered for a more complete picture of nanotechnology's social and economic impact. This, in turn, lends support to the Precautionary Principle Objection: given these other considerations, risk aversion seems less to be a reasonable strategy, to the extent that potential benefits seem to far outweigh potential harms in aggressively pursuing nanotechnology.

But if this is such a compelling argument, why do we not see more people (explicitly) advance it? One reason seems to be that this sort of objection requires making mid- and far-term speculations about nanotechnology, which is always risky business, especially if it also raises other ethical and societal concerns. For instance, nanotechnology's role in the military might resurrect questions from the Cold War about mutuallyassured destruction and first-strikes. And many of the more interesting predictions about nanotechnology revolve around "molecular manufacturing" - an advanced form of nanotechnology that involves building designer objects one molecule at a time, raising the possibility of creating virtually any object we want, from food to weapons; however, this is very much an area that many or most mainstream scientists are reluctant to speculate about or openly dismiss [39]. And if molecular manufacturing were more widely predicted to be plausible, it may open a Pandora's Box of potentially disruptive and harmful effects on global trade and therefore politics, all complex questions that would then need to be addressed. Again, all this is speculative, so it is unclear what the possible far-term harms are and their probability, even if we are confident about far-term benefits.

The Future Harms Objection also forces us to confront the unpleasant question of what the limits are to our right not to be unjustifiably harmed: is it morally permissible to risk the health of, say, 1,000 or even 10,000 manufacturing workers and consumers today, if we can save 100,000 or 1,000,000 other lives later through the aggressive pursuit of nanotechnology? (These numbers, of course, are very difficult to forecast and are used merely as examples here.) Also, speaking of future generations, if federal funding is a zero-sum game, i.e., funding nanotechnology now takes away from the budget in another area, what about lives today that could have been saved with the funding currently diverted to nanotechnology, which is more an investment in tomorrow? These are questions that have no simple or universally-accepted answer, much less one that a legislator would want to tackle.

As such, this particular objection, as with the Other Harms Objections, again depends on other factors, namely rights, that cannot easily be reconciled on an accounting ledger of benefits versus harms. So if we are to extend the time horizon in the Other Harms Objection to make the Future Harms Objection, then it seems only fair that we must consider long-term harms of not having stricter laws as well - again, leading us back to a probable stalemate in the debate.

Though the Future Harms Objection appears to be stronger than its predecessor, the numbers involved are too difficult to quantify and forecast, as well as difficult to process in the framework of human rights. Further, though this objection is related to the Other Harms Objection, the objectors seem to represent very different positions: to the extent that mainstream scientists and nanotechnology executives support the Other Harms Objection, they may be reluctant to speculate about nanotechnology's promise beyond the near future, fragmenting support for the Future Harms Objection.

Of course, none of this speaks to the objection's soundness or logic. If we can reasonably project overall benefits and harms across time, and if the benefits sufficiently outweigh the harms, and if the relevant human rights are not unjustifiably violated, then the Future Harms Objection could be defensible. But these variables are perhaps too speculative to nail down with much confidence; therefore, the premise P3 that it was designed to attack seems to survive, or at least it has not been convincingly shown that it should be rejected.

\section{(g) Better-Us-Than-Them Objection}

The final objection we will consider in this paper is not one we see explicitly in nanotechnology-related literature, but it is one we have heard anecdotally. It might start by pointing out that many democratic nations, such as the US, occupy a fortunate position in 
the world where they can afford to be reflective about matters of ethics and philosophy. We have that luxury, but many other countries do not; they are embroiled in a more desperate fight for survival. And if the means became - and at some point will become available to them, chances are good that they will pursue and exploit nanotechnology without such strict regulations, if any regulations at all, to impede research and development, perhaps for the base reasons of national glory or military superiority and even at the expense of their own citizens and environment.

Do we really want nanotechnology to be dominated by other nations of whom we are already suspicious? Even if we can take the higher moral ground and lay aside our national prejudices, it does not change the fact that the other country will probably not - and not care. Imagine then how the world and beyond might look, if that foreign country were to be the ones who control nanotechnology, which could be the key to controlling literally everything.

So if not only for this reason, we must keep our lead in developing nanotechnology; we don't want to live on Planet Kim Jong-il. For the same reason, even if we think our nano-future is bleak anyway, it could be worse if the wrong nations were to be the ones who shaped it the most.

So we must "own" nanotechnology and proceed full speed ahead, without stricter regulations to impede us; and when we do, we can take a rest and become reflective again, returning our attention to EHS matters. By deferring that moment of moral questioning from now to then, we would then be in a time and a place when we can do something about our angst and any harm previously caused. We can give nanotechnology to other countries, if we're so concerned about justly distributing tools that can help humanity. We can try then to build that utopia we had only read about. Even if we can't do any of this, this possible world seems much nicer that the one where, say, a non-democratic country had its way with the world, to the extent that our utopia is more utopian and our values more valuable (to us at least).

That's why we - and by "we", I mean your respective nation - need to dominate nanotechnology research, even if some problems are caused along the way, which appear to be smaller problems within a much larger picture. Now, this is not the ideal scenario, but it is a rationale one. We would rather not be in a dangerous competition with another country or countries; but the fact remains that we are. And that's the difference between philosophy ethics and real-world ethics. Or so this objection might go.

\section{Analysis}

As with the previous two objections, this one disputes premise P3 in our formalized argument. It does not deny that there may be EHS harms from nanotechnology (i.e., it does not dispute conclusion $\mathrm{C} 1$ ), but it asserts that EHS harms are not an unacceptable consequence if stricter laws would cause greater harm, thereby questioning conclusions $\mathrm{C} 2$ and $\mathrm{C} 3$. In fact, it argues that greater harm would be caused by not aggressively pursuing nanotechnology and allowing other nations to take the lead; therefore, EHS harms are the lesser of two evils and should be preferred and accepted over the alternative.

This is a very pragmatic - and forgivable position to take on the role of ethics in society and especially in a democracy. But where risk-aversion may not always be the best strategy as the previous objection asserted, being pragmatic also might not be the best course of action or the right thing to do.

For instance, consider the ban on human cloning that exists in some countries. It would be pragmatic to argue that at some point, somewhere in the world, someone will clone a human being. If this is an inevitable event, then it would be better if we (our nation) were the ones who cloned a human first; we could at least ensure that safeguards were in place, that the clone could be treated humanely, that we would put any knowledge we gained to good use, etc. But if this line of reasoning fails to work in human cloning (as well as other cases such as an arms buildup), then it seems to suffer from the same condition when applied to nanotechnology.

Further, as we discussed in the previous two objections, this objection ignores the role of human rights, the rights of citizens today to not be harmed; or it at least is willing to sacrifice these rights for a future benefit, which is a controversial position to adopt.

Finally, there is no guarantee or even reasonable assurance that if we pursue nanotechnology without restriction, then our nation will have the lead; it is 
very much still an open field. So without some safeguards in place at the national level if not also globally (such as treaties to limit the threat of mutually-assured destruction, in the case of an arms build-up), there is still potential for catastrophe to occur, especially if we move forward recklessly. And a more sensible or alternative solution to the situation posited by the objection seems to be that we should advocate greater regulations and oversight - or at least cooperation as a first step - on a global scale, if stricter regulations only at the national scale would impede that particular nation.

The belief that something is inevitable, whether nanotechnology or Armageddon, does not seem to be a good enough reason to rush towards it, especially if we can buy some time by moving a bit slower precious time needed to perhaps develop safeguards to mitigate any associated negative impacts.

\section{An Interim Solution?}

A full defense or analysis of the preceding objections, particularly the last three, is beyond the scope and goals of this paper, but there seems to be enough reason to believe that they are not entirely without merit. At the same time, there does not (yet) seem to be enough there to believe that the stricter-law argument should be rejected. So an interim or compromise solution may be needed now to cover both contingencies.

Moreover, even if stricter laws and regulations are ultimately justified, there are good reasons to think that they cannot be enacted anyway, or at least face stiff resistance with lawmakers and regulatory agencies, particularly in the US. Clarence Davies, the author of the Woodrow Wilson International Center report that sparked today's stricter-law debate, even admits that: "In the U.S. political system, it has never been easy to pass new laws regulating commercial products. In the current political climate, it is close to impossible" [40]. Changing regulatory policy is likewise a formidable challenge.

That is to say, the US legislative and regulatory systems are notorious for being complicated and mired in debate, so barring an urgent need - which many believe has not yet been established for nanomaterials - it does not seem optimistic to think that new laws or stronger regulations can be enacted in the near future, even if needed. But perhaps we can suggest a simpler solution here.

\section{Running Faster to Catch Up}

There is a sense with many that nanomaterials found in today's products have not been established yet as a clear and present danger, which may be part of public, legislative and regulatory hesitation to propose dramatic changes to current rules. Under this reasoning, rushing new laws or regulations through until more facts are revealed may be the same kind of mistake as rushing nanotechnology products into the marketplace without fully considering their impact on health, environment or even society and ethics.

But we can acknowledge this position while at the same time be prepared to adopt new regulations if and when more studies show that nanomaterials are indeed harmful and that new laws are warranted. That is to say, even if we are not ready to call for stricter policies now, we can and perhaps should have a contingency plan or "Plan B" developed, discussed and ready to be implemented, should more compelling evidence be presented in favor of stricter laws. (The trick here, of course, is to specify the details of such a "Plan B", which too is beyond the scope and goals of this paper.) If we adopt a wait-and-see attitude towards nanomaterials, then it is incumbent upon us to aggressively conduct safety testing.

However, a critical point in the nanotechnology regulatory debate is that current testing methods may be inadequate against nanomaterials and products, so it is not clear that more testing will get us far if we do not improve those methods; therefore, it is also incumbent upon us to aggressively develop new testing methods in order to conduct EHS testing effectively.

The proposed solution, then, is rather than slowing the nanotechnology industry down through more regulations, as some claim they would, regulatory planning as well as EHS testing and research need to run faster and catch up - just as experts have called upon ethics to do [41]. Starting a serious dialogue today with policymakers would help compensate for the slow time-to-action for creating new laws, particularly if we are just idly waiting for more research to come out that would compel action. And continuing to support and fund research into nano- 
material safety is critical to evolve the safety standards that exist in current laws and regulations. Progress is being made in this area, as the aforementioned UCLA researchers last year, and others since then, showed by developing a new testing model to evaluate the safety and health risks of engineered nanomaterials.

Further, if we can improve testing methods, then we may not need new laws or stronger regulations, at least in the meantime. Where current laws and regulations require materials to pass certain safety and health standards, we may be able to simply evolve and raise those standards as scientific understanding and testing methods evolve, as opposed to erecting new regulations. This would only require that current policies recognize and utilize the latest advances in safety and health testing, which is a reasonable expectation. (Note: The WWICS report criticizes some of the relevant regulations as being unclear or having loopholes or failing to apply to critical industries, such as cosmetics, so improved materials testing admittedly would not solve those deficiencies. However, those problems exist independently from nanotechnology: they are not specific to nanomaterials and have been issues for some time now. As such, they present a broader challenge in the field of a regulatory reform and therefore are not so much addressed in our discussion here.)

Without developing new testing methods, it does not seem that new or stricter laws can address risks posed by nanomaterials anyway, if current methods fail us. Therefore, incorporating these new standards is the salient point in the recommendation to create stricter laws and regulations. Or to put it another way, if current testing methods are inadequate to show that nanomaterials are harmful, and we know that they are harmful at least in some cases, then any new or stronger law that is still based on these current methods does not seem to add much value, just more barriers to business.

For instance, would harsher civil and criminal penalties or more detailed environmental impact reports cause company executives to act any differently, if no different methods were available to support or refute previous claims of product and materials safety? They would most likely run more of the same tests to arrive at the same conclusion. This would seem to be an instance of GIGO or "garbagein-garbage-out", where without new testing methods, we are using inadequate processes that inevitably generate inadequate conclusions.

If it makes sense to push harder for better testing methods, that still leaves a problem of a stop-gap measure in the meantime, since new funding takes a significant amount of time to disburse and research often proceeds slowly as well. One solution is to accept the proposal for the nanotechnology industry to regulate itself, as an alternative to doing nothing. To repeat a key point in our discussion of the Selfregulation Objection above, the objection itself does not dispute the soundness of the stricter-law argument. In fact, it agrees that more regulations are needed, but that the nanotechnology industry should be the one to create and implement them, since the industry knows nanotechnology the best and has a direct interest in sustaining the field.

At best, self-regulation will eliminate EHS risks in nanotechnology to at least some degree; at worst, it seems that it would not create any additional EHS risks but at least represents a good-faith effort to mitigate those risks. If and when governmental regulations are needed, that process can be informed by the prior exercise of self-regulation.

\section{Open Questions}

Of course, the interim solution proposed above is a conceptual framework, and many real-world details still need to be worked out. For instance, are there any examples of "Plan B" approaches to suggest that such a proposal can actually work? What are the specific steps we would need to take to strengthen preregulatory planning, methods for testing materials, and toxicology testing? Do we need (paradoxically) a legal basis for ensuring that this greater focus on EHS risks and testing actually occurs, for example, by stipulating that some percentage of all nanotechnology research funds will go towards these areas?

How do we know that more and faster study of the EHS aspects of nanotechnology can keep up with the full-throttle research and development (R\&D) and commercialization of nanotechnology in not just the US but also abroad? And how much more funding is needed for ethics and risk to catch up with R\&D? If other nations do not focus as much on EHS risks, would the US (or any other nation that adopts such an interim solution) need to compensate with even more 
funding, given that nanotechnology ultimately knows no national boundaries and impacts the entire world, especially given a global economic ecosystem?

And if additional funding is warranted, where would that come from? Would it be diverted from other programs that are working on current cures for current ills, outside of nanotechnology's risks (which seem to be future risks, as opposed to actually harming people or the environment right now)?

These are all good questions, and we do not intend to present a complete solution here; but we merely hope to provide a starting point for discussion towards a feasible solution while the nanotechnology regulation debate rages on. Moreover, to the extent that nanotechnology is a highly interdisciplinary area, we would expect that collaboration among lawmakers, scientists, ethicists, economists, and so on would be needed to account for the complicated issues arising from nanotechnology - more than just what a few ethicists can achieve here.

\section{Conclusion}

Though we would like to avoid the difficult comparison of nanotechnology's possible benefits with its possible harms in this paper, it seems that what is known now - and not just speculation, albeit educated is that nanotechnology products today provide only incremental value or changes to existing products, i.e., they represent "better mousetraps" and not yet the revolutionary products predicted. On the other hand, the risks that nanomaterials pose today may be severe, possibly including death of animals and people.

Therefore, we conclude that there is reason to think that current laws do not fully account for nanotechnology, if potentially-hazardous nanotechnology products are reaching the marketplace. Nanotechnology, though technically not a "new" science, nevertheless introduces new materials that may defy current testing and safety standards not designed with nanosized particles in mind. And research already indicates that nanomaterials are hazardous to the environment and human health, which is made all the more troubling considering that some nanomaterials come into direct contact with human beings, such as that in sunblock rubbed into one's skin.

But here's an important caveat: even if current laws are inadequate, would new or stronger laws be enough to fill that gap? In other words, the regulatory debate has been centered on the question of whether we need more regulation; but the more relevant question may be, why are current laws ill-equipped to deal with nanotechnology? The answer, or at least the complete answer, might not be that we are missing some law or process, but that the testing methods and standards built into existing laws have not caught up with the pace of nanotechnology.

While cleaning up and streamlining our maze of regulatory processes would certainly be helpful in general, unless we can quickly advance methods to more effectively test for environmental, health and safety risks in nanomaterials, new or stricter laws may serve to only slow down the industry through procedural changes rather than to improve our evaluation of nanomaterials through substantive or qualitative changes in how we approach such materials.

So our suggestion is, rather than causing the nanotechnology industry and business to slow down now - which risks being a knee-jerk reaction to create more laws in the face of a problem - other areas can be stimulated to quickly catch up. Regulatory preplanning needs to catch up with the growing number of studies that confirm nanotechnology's EHS risks, in case new laws are ultimately needed. And testing methods and standards need to catch up to better confirm the safety of nanomaterials, which could occur within the framework of existing laws, and screen out the products that are hazardous to our environment, health and safety. At the same time, we can take the nanotechnology industry up on its offer to regulate itself; there does not seem to be any harm in that, especially if the alternative is to do nothing.

There are several advantages of such a solution. First, while benefits today in nanotechnology (i.e., better sunblock, better sports equipment, better pants, etc.) might not justify its risks, this might not remain the case in the future. And overburdening the nanotechnology industry with regulation, though well intended, may ultimately cause more damage than good. So we need to find a reasonable balance that responsibly promotes innovation in nanotechnology while at the same time safeguards EHS interests - in addition to other interests that nanotechnology may run up against as the field matures, such as privacy.

Second, a compromise may be needed anyway, once we recognize that there are significant chal- 
lenges in creating new laws or regulations, and that there is presently little public awareness of these issues that might apply pressure to policymakers. Neither business interests nor EHS interests will be going away any time soon, nor do we really want either to. But we have seen the undesirable effects of placing too much focus on either business or EHS, so finding a balance between these legitimate interests is needed, particularly in a democracy that values a diversity of opinions.

Third, such a solution may serve to accelerate the industry responsibly - giving us new confidence that our nanoproducts are safe or identifying the ones that are not. Research into new testing methods would also give us new insights into nanomaterials, perhaps even new applications.

In Greek mythology, Prometheus - the titan of forethought - gave fire to mankind as a gift (though he was summarily punished by the gods with unending torture). In nanotechnology, we also have a rare gift that can enable us to profoundly change our world. But just as we should not play with fire before we learn how to control it or its risks, commonsense requires the same for nanotechnology. With more effective regulations and new safety testing methods, we can help ensure that nanotechnology does not burn our world down.

\section{References}

1. Davies JC (2006) Managing the effects of nanotechnology. A report published by Woodrow Wilson International Center for Scholars, January

2. In this paper, we will use "laws" and "regulations" interchangeably for the sake of simplicity, though we recognize a distinction between the two, which is not material to this discussion

3. For instance: Jasanoff S (2005) Designs on nature: science and democracy in Europe and the United States. Princeton University Press, Princeton

4. Oberdörster E (2004) Manufactured nanomaterials (Fullerenes, C60) induce oxidative stress in the brain of juvenile largemouth bass. Environ Health Perspect 12(10):10581062, July

5. Merkle R (1997) It's a small, small, small, small world. MIT Technology Review 25, Feb/March

6. Colvin V, Wiesner M (2002) Environmental implications of nanotechnology: progress in developing fundamental science as a basis for assessment, a keynote presentation delivered at the U.S. E.P.A.'s "Nanotechnology and the Environment: Applications and Implications STAR Review Progress Workshop" in Arlington, VA, August 28
7. Gibbs L, Tang M (2004) Nanotechnology: safety and risk management overview. NNIN Nanotechnology Safety Workshop at Georgia Institute of Technology, December 2

8. Ibid.

9. Ibid.

10. For instance: David Berube, "Regulating Nanoscience: A Proposal and a Response to J. Clarence Davies", Nanotechnology Law \& Business, December 2006, vol. 3, issue 4: 485-506.

11. For instance: Australian Green Party, "Call for moratorium on nanotechnology, Australian Associated Press article dated March 17, 2007; Friends of the Earth (FOE), "Nano-ingredients Pose Big Risks in Beauty Products: Friends of the Earth report highlights unregulated risks of nanoparticles in cosmetics and sunscreens", press release dated May 16, 2006; and ETC Group, "No Small Matter II: The Case for a Global Moratorium", report dated April 2003.

12. U.S. Environmental Protection Agency, "EPA seeking PFOA reductions", January 25, 2006 press release.

13. Ibid.

14. Brian Ross/ABC News, "Government moves to curb use of chemical in teflon", January 25, 2006.

15. For instance: Ashok Agarwal, et al., "Effect of cell phone usage on semen analysis in men attending infertility clinic: an observational study", 62nd Annual Meeting of American Society of Reproductive Medicine, October 23, 2006.

16. Reuters News, "Testing cell phone radiation on human skin", March 3, 2006.

17. For various formulations, see for instance: Wecker J, Moor $\mathrm{J}$ (2006) The precautionary principle in nanotechnology. Int J Appl Philos 20(2): 191-204, Fall

18. Brian Ross, ibid.

19. U.S. National Nanotechnology Infrastructure Network website, accessed on June 6, 2006: http://www.nnin.org/ nnin_what.html.

20. Friedlander SK, Pui DYH (2003) Emerging issues in nanoparticle aerosol science and technology. A report published by U.S. National Science Foundation, November

21. Nel A, Xia T, Mädler L, Li N (2006) Toxic potential of materials at the nanolevel. Science 311(5761): 622-627, February

22. Sunstein CR. Cost-benefit analysis and the environment. Ethics 115(2): 351-385

23. National nanotechnology initiative: leading to the next industrial revolution. A report published by US National Science and Technology Council's Committee on Technology, February 2000

24. Macoubrie J (2005) Informed public perceptions of nanotechnology and trust in government. A report published by Woodrow Wilson International Center for Scholars, September

25. For instance: Thomas Hobbes, Leviathan (1651), chapter 14 , section 8; and many other subsequent political scientists.

26. For a more complete discussion of the Precautionary Principle, see Weckert and Moor, ibid.

27. Witteveen WJ (2005) A self-regulation paradox: notes towards the social logic of regulation. Electronic Journal of Comparative Law 9(1), January

28. Ibid. 
29. Ibid.

30. Axelrod R. (1984) The evolution of cooperation. New York: Basic Books, 1984.

31. "Where has my money gone? Government nanotechnology funding and the $\$ 18$ billion pair of pants", a report published by Cientifica, January 2006.

32. Leif Wenar, "Rights", The stanford encyclopedia of philosophy, Winter 2005 edition, Edward N. Zalta (ed.).

33. Ibid.

34. Ibid.

35. Ibid.

36. Research assistance for this section provided by Tihamer Toth-Fejel, M.S.E.E., General Dynamics Advanced Information Systems.
37. Roco MC, Bainbridge WS (eds) (2001) Societal implications of nanoscience and nanotechnology. A report published by the US National Science Foundation 3, March

38. Uldrich J (2006) Nanotech of the north. The motley fool, March 26

39. Baum R (2003) Nanotechnology: Drexler and Smalley make the case for and against 'molecular assemblers'. Chem Eng News 81(48): 37-42, December 1

40. Davies JC (2006) Managing the effects of nanotechnology. A report published by Woodrow Wilson International Center for Scholars, 10, January

41. Mnyusiwalla A, Daar AS, Singer PA (2003) 'Mind the gap': science and ethics in nanotechnology. Nanotechnology 14(3): R9-R13, March 